\title{
The Mothers and Children's Environmental Health (MOCEH) study
}

\author{
Byung-Mi Kim $\cdot$ Mina Ha $\cdot$ Hye-Sook Park $\cdot$ Bo Eun Lee $\cdot$ Young Ju Kim $\cdot$ \\ Yun-Chul Hong · Yangho Kim · Namsoo Chang $\cdot$ Young-Man Roh · \\ Boong-Nnyun Kim $\cdot$ Se-young Oh $\cdot$ Eun-Hee Ha $\cdot$ The MOCEH Study Group
}

Received: 22 February 2009/Accepted: 7 July 2009/Published online: 24 July 2009

(c) The Author(s) 2009. This article is published with open access at Springerlink.com

\begin{abstract}
The MOCEH study is a prospective hospitaland community-based cohort study designed to collect information related to environmental exposures (chemical, biological, nutritional, physical, and psychosocial) during pregnancy and childhood and to examine how exposure to environmental pollutants affects growth, development, and disease. The MOCEH network includes one coordinating center, four local centers responsible for recruiting pregnant women, and four evaluation centers (a nutrition center, biorepository center, neurocognitive development center, and environment assessment center). At the local centers, trained nurses interview the participants to gather
\end{abstract}

The members of the MOCEH Study Group are listed in the Appendix.

\section{B.-M. Kim · H.-S. Park · B. E. Lee · E.-H. Ha $(\bowtie)$}

Department of Preventive Medicine, School of Medicine, Ewha

Medical Research Center, Ewha Womans University, 911-1 Mok

6-dong, Yangcheon-Gu, Seoul, Korea

e-mail: eunheeha@ewha.ac.kr

M. Ha

Department of Preventive Medicine, Dankook University

College of Medicine, Cheonan, Korea

\section{Y. J. Kim}

Department of Obstetrics Medicine, College of Medicine, Ewha Medical Research Center, Ewha Womans University, Seoul, Korea

Y.-C. Hong

Department of Preventive Medicine, Seoul National University

College of Medicine, Seoul, Korea

\section{Y. Kim}

Department of Occupational and Environmental Medicine, Ulsan University Hospital, University of Ulsan College of Medicine, Ulsan, Korea information regarding their demographic and socioeconomic characteristics, complications related to the current gestation period, health behaviors and environmental factors. These centers also collect samples of blood, placenta, urine, and breast milk. Environmental hygienists measure each participant's level of exposure to indoor and outdoor pollutants during the pre- and postnatal periods. The participants are followed up through delivery and until the child is 5 years of age. The MOCEH study plans to recruit 1,500 pregnant women between 2006 and 2010 and to perform follow-up studies on their children. We expect this study to provide evidence to support the hypothesis that the gestational environment has an effect on the development of diseases during adulthood. We also expect the study results

\section{N. Chang}

Department of Nutritional Science and Food Management, Ewha Womans University, Seoul, Korea

Y.-M. Roh

Institute of Environmental and Industrial Medicine, Hanyang

University, Seoul, Korea

B.-N. Kim

Division of Child \& Adolescent Psychiatry, Department of Psychiatry and Institute of Human Behavioral Medicine, Seoul National University College of Medicine, Seoul, Korea

S. Oh

Department of Food and Nutrition, Kyung Hee University, Seoul, Korea

The MOCEH Study Group

Seoul, Korea 
to enable evaluation of latency and age-specific susceptibility to exposure to hazardous environmental pollutants, evaluation of growth retardation focused on environmental and genetic risk factors, selection of target environmental diseases in children, development of an environmental health index, and establishment of a national policy for improving the health of pregnant women and their children.

Keywords Prenatal exposures - Child development . Cohort study $\cdot$ Design

\section{Introduction}

Childhood diseases that may be associated with environmental exposures are major public health concerns in Korea and around the world [1-5]. The Child Health Environmental Research (CHEER) study recently conducted in Korea showed that the prevalances of asthma, atopic diseases, and behavioral disorders among 9-year-old children were $8.1,17.5$, and 3.3\%, respectively [6].

Researchers in many countries have set up cohort studies designed to assess the consequences of prenatal exposure to environmental pollutants. In the US, the National Children's Study (NCS) is expected to characterize exposure contrasts in its cohort of 100,000 pregnant women from various locations across the US and to estimate exposure-response relationships from childhood to adulthood [7]. In England, the Avon Longitudinal Study of Parents and Children began collecting genetic and phenotypic information on 15,000 pregnant women, their partners, and children in the early 1990s, and the study continues to obtain follow-up data on over 11,000 families [8]. The Danish National Birth Cohort1 and a Norwegian study have collected data from the prenatal period to 18 months after delivery on 100,000 live births [9]. In Spain, the INMA (INfancia y Medio Ambiente Environment and Childhood) plans to follow up on a sample of 3,100 pregnant mothers and their newborns [10]. The Tohoku Study of Child Development recruited 1,000 healthy pregnant women from two hospitals in Sendai, Japan [11], and the Hokkaido Cohort Study was conducted on a group of 20,000 children between 2002 and 2005 [12]. The Japanese government also plans to integrate these birth cohort studies and set up a live birth cohort study of 60,000 individuals to be carried out between 2010 and 2020 [12].

These studies investigated a wide spectrum of environmental pollutants and their effects on multiple outcomes of interest, including pregnancy outcome, neurodevelopment, asthma, obesity, and pubertal development, in order to determine how pre- and post-natal environmental exposures affect growth, development, and health from early fetal life until young adulthood [7-18].

\section{Scope of research}

In Korea, the National Environmental Health Action Plan (NEHAP) [19] developed by the Ministry of Environment outlines strategies for eliminating environmental health hazards and reducing their adverse effects on pregnant women and their children [20-28]. In 2006, the Mothers and Children's Environmental Health (MOCEH) program, a multi-center prospective cohort study, began as an initiative of the NEHAP. In the present study, we attempt to introduce the planning processes, study design, protocols, current status, and future directions of the MOCEH study.

The objective of the MOCEH study is to (i) collect information on environmental exposures (chemical, biological, nutritional, physical, and psychosocial) during pregnancy and childhood and (ii) to examine how exposure to environmental pollutants affects growth, development, and disease. Using research-based information, we aim to provide a foundation for improving the health, development, and well-being of children in the future. Furthermore, the MOCEH study will provide valuable information based on evaluations of latency and age-specific susceptibility to exposure to hazardous environmental pollutants and evaluations of growth retardation focused on the influence of environmental and genetic risk factors. The results of the MOCEH study will facilitate in the selection of target environmental diseases in children, the development of an environmental health index and the establishment of a national policy for improving the health of pregnant women and their children.

\section{Study area and collaboration}

The MOCEH network consists of nine centers: a coordinating center, a biorepository, an environmental exposure assessment center, a nutrition assessment center, a neurobehavioral assessment center, and four local centers. The four local centers are located in Seoul (a metropolitan area), Ulsan (an industrial area), and Cheonan (a mediumsized urban area). Each center has a community-based collaborative network of university hospitals, local clinics, and community public health centers (Fig. 1).

The Seoul center is a community-based collaborative network composed of Mok-dong Hospital (Ewha Womans University) and Yangcheon Community Health Center. Seoul was selected as a study area because of its large population, heavy volume of traffic, serious air pollution and 
Fig. 1 Community-based collaborative network Note: ${ }^{\mathrm{a}} I R B$, Institutional Review Board; ${ }^{\mathrm{b}} O B / G Y N$, Obstetrics and Gynecology; ${ }^{\mathrm{c}} \mathrm{PHCC}$, Primary Health Care Center in Community

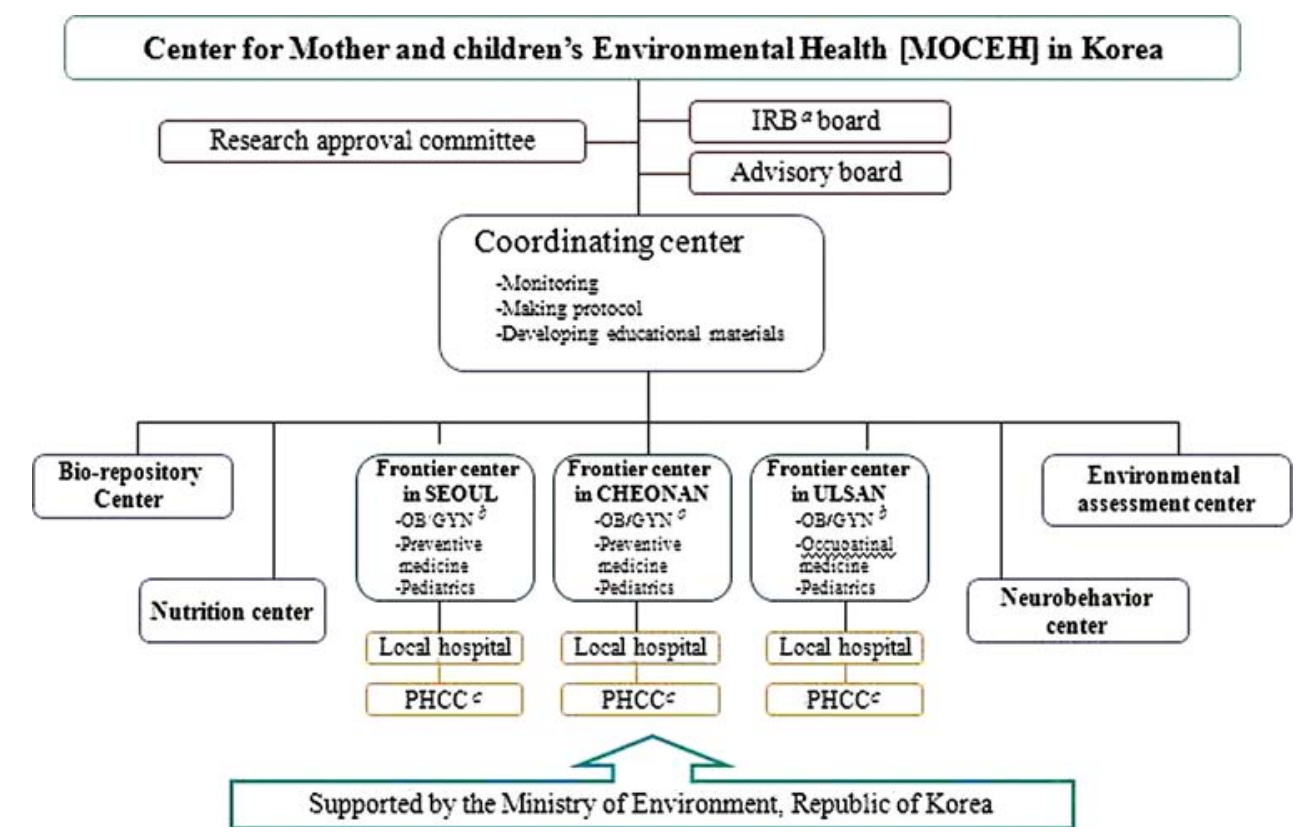

high-density apartments [29]. The Cheonan Asan center works in collaboration with Dankook University Hospital, Asan Community Health Center, four local obstetrics and gynecological clinics and a pediatric clinic. The cities of Cheonan and Asan are neighboring cities located in Chungnam Province, Korea, and they are relatively clean cities with a mixture of rural and high-tech industrial (mainly the informational technology and semiconductor industries) areas [30]. Ulsan, the largest industrial city in Korea, is a home to a variety of industries, such as the shipbuilding, car manufacturing, and petrochemical industries [31]. The Ulsan center is affiliated with several organizations. The Ulsan University Hospital, where the Ulsan center is located, provides full administrative support to the Ulsan center. Ulsan Donggu Public Health Center provides administrative support to the Ulsan center and refers pregnant women of the Ulsan center [32].

A community partner involvement is a critical part of the MOCEH study. We periodically organize meetings with community partners (public health centers and private clinics) to discuss the processes and progress of the study, and we provide our community partners with relevant information interactively.

\section{Study design}

\section{Overview}

The MOCEH study is a prospective hospital- and community-based cohort study designed to investigate the effects of pre- and postnatal environmental exposures on growth, development, and health from early fetal life into young adulthood. Pregnant women, their partners, and their children will be the subjects of these investigations. The Institutional Review Board at Ewha Woman's University, Seoul, South Korea has reviewed and approved the study protocol.

\section{Planning process}

The development process of the MOCEH study is shown in Fig. 2. The Steering Committee of the Mothers and Children Environmental Health (SC-MOCEH) study has further developed the conceptual framework for the study, established an administrative structure for the management and implementation of the study and outlined the steps involved in planning and implementing the study.

Organizing an advisory committee The MOCEH Advisory Committee (AC-MOCEH) and its working group, which is comprised of an independent panel of experienced researchers in the fields of obstetrics, pediatrics, nutrition, and environmental health, discussed the selection of the

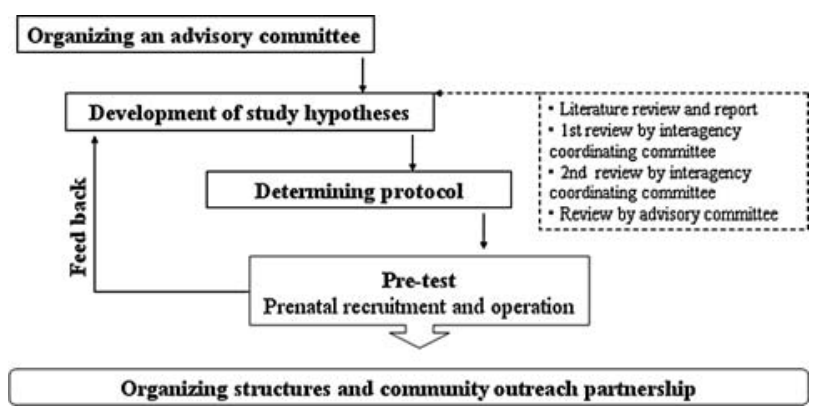

Fig. 2 Planning steps of the MOCEH 
primary topics of interest to be addressed in the MOCEH study.

Development of hypotheses In order to develop the hypotheses to be tested in the MOCEH study, the working group reviewed the NCS's and WHO's lists of hypotheses relevant to studies on the environmental health of mothers and their children in Korea. The working group searched for published papers, reports, and other documents concerning the health and environmental exposures of mothers and their children in order to determine which topics are most relevant. The core study hypotheses were generated on the basis of these reviews.

Protocol development The initial development of the schedule, types of exposure to be assessed, and outcome measures were guided by a series of hypotheses concerning important unanswered questions in the field. These hypotheses define relevant physical, chemical, biological, and psychosocial factors that can affect one or more of the following: pregnancy outcomes, child growth and development, childhood disorders such as asthma, and the psychological health of children. All aspects of the study design were finalized after taking the core hypotheses, financial resources, utility for future investigations, and ethics of the study into consideration.

\section{Core hypotheses in MOCEH}

The MOCEH is hypothesis-driven and addresses a series of specific questions pertaining to the influence of the environment (chemical, biological, and physical) on the health, growth, development, and risk of disease in children. The goal of the investigation is to identify the etiologically important gene-environment interactions, as well as the factors that modulate individual susceptibility to environmental exposures. As the MOCEH is implemented, new questions will emerge and be added to the analysis, and some may become outdated and no longer relevant. Representative questions that the MOCEH will address are provided below:

1. What is the role of bio-aerosols in the etiology of adverse birth outcomes and health problems in children? Many studies have investigated the relationship between air pollution exposure and birth outcomes such as low birth weight (LBW), stillbirth, intrauterine growth retardation (IUGR), and premature birth [28]. Air pollutants have been associated with infant mortality and with health problems in children such as asthma and allergies [33-36].

2. What is the role of heavy metals in the etiology of adverse neurobehavioral outcomes? Heavy metal exposure (lead, mercury, cadmium, and manganese) has been associated with impaired intrauterine growth, low birth weight, postnatal growth impairment, and neurodevelopmental problems [37-39]. Several studies have reported a relationship between occupational heavy metal exposure and adverse reproductive outcomes, such as spontaneous abortion, growth retardation, congenital malformations, and fetal death [40, 41].

3. What is the role of endocrine-disrupting chemicals (EDC) such as sisphenol A (BPA) and phthalates in abnormal fetal growth and neurobehavioral outcomes? There is some evidence suggesting that prenatal exposure to BPA has an impact on fetal growth [42-46]. Another concern, specifically with regard to neurodevelopment, is the observed correlation between exposure to phthalates and circulating thyroid hormone [47].

4. What are the interactions between environmental factors and susceptibility genes in the development of disease? Several investigators have reported that specific CYP1A1 genotypes confer a risk for reduced birth weight. The CYP1A1 polymorphism might alter the risk for reduced birth weight associated with exposures to $\mathrm{PM}_{10}$ along with other pollutants such as: $\mathrm{CO}, \mathrm{NO}_{2}$ and $\mathrm{SO}_{2}$ [48].

Therefore, the MOCEH will provide an opportunity to study the complex interrelationships between environmental factors and genetic susceptibility factors involved in adverse health outcomes during pregnancy and childhood.

\section{Study protocol}

Figure 3 gives the details of data collection during the MOCEH study.

\section{Prenatal visits}

Prenatal examinations are conducted in a clinical setting during the first and third trimesters. Ultrasonography is performed during the first and third trimesters. Information on demographics and environmental exposures is obtained through a comprehensive questionnaire. Nutritional status is assessed by the 24-h recall and the food frequency questionnaire (FFQ). Biological samples (blood and urine) are also obtained. The women's spouses/partners are also asked to complete a questionnaire survey and provide biological samples within the first trimester.

\section{Birth}

The birth of the child is a crucial part of the study for a number of reasons. For example, it is necessary to collect 
Fig. 3 MOECH study process

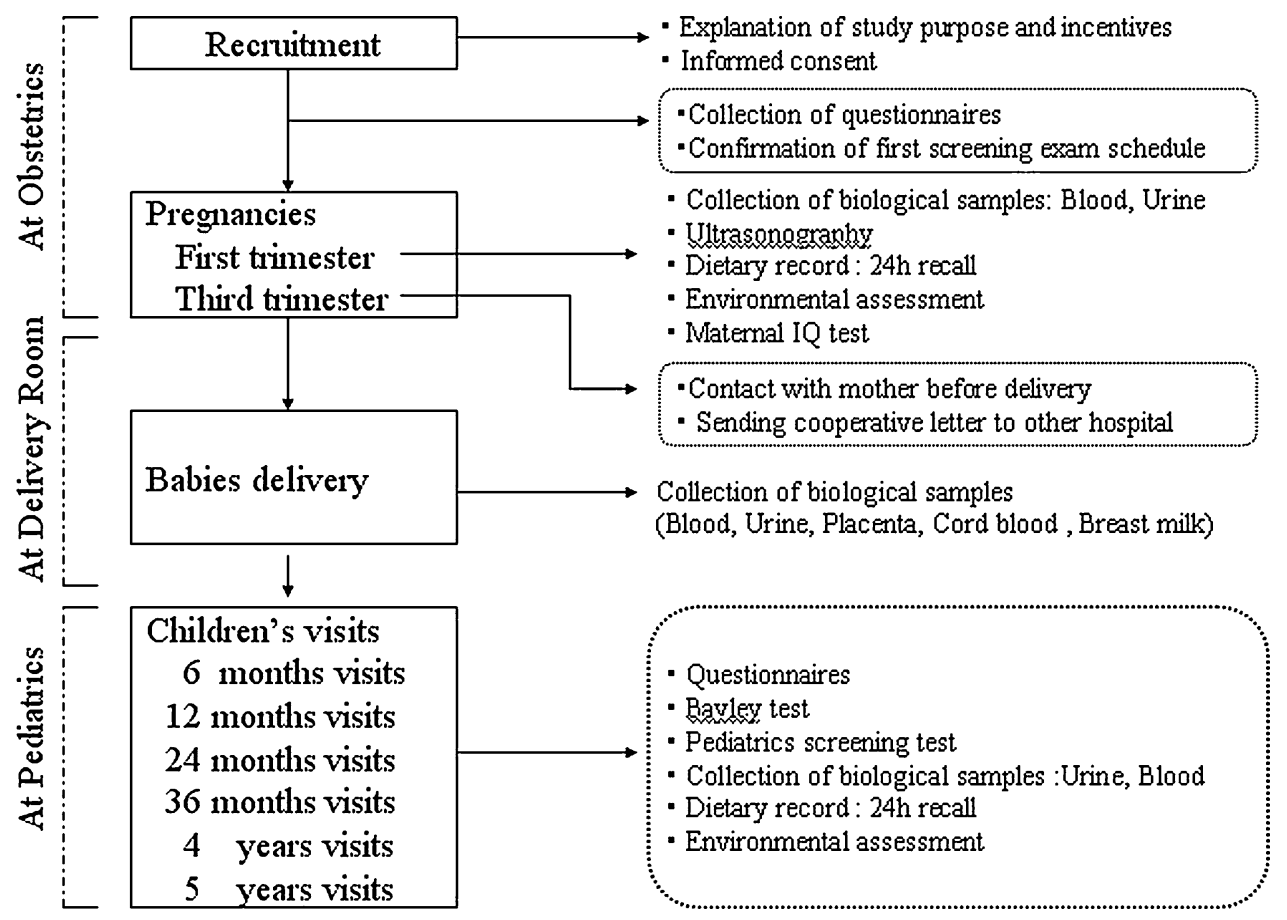

maternal blood, cord blood, and placental tissue, and to obtain information about the labor and delivery from medical records. The reliable collection of biological samples at birth is one of the most challenging aspects of this study. Neonatal urine and samples of colostrum are also being collected.

Follow-up

Data is collected from children at 6,12 , and 24 months of age and then again at the age of 5 . These data are collected through developmental and physical assessments, caregiver interviews, collections of biological samples, Bayley ScaleII results, assessments of nutritional status (24-h recall and semi-quantified FFQ), and environmental samples from the child's home. Details of the methods used to collect data during the MOCEH study are outlined in the following figure.

Enrollment and informed consent

The MOCEH study plans to recruit more than 1,500 women (and their husbands) during the early period of pregnancy (less than 20 weeks of gestational age) between 2006 and 2010. Inclusion and exclusion criteria are shown in Table 1. At the initial prenatal visit, the participants are asked to provide written informed consent on behalf of themselves and their children to participate in the followup study.
Table 1 Inclusion and exclusion criteria for the MOCEH study

Inclusion criteria

1. Women who are in the first and trimester of pregnancy at the time of the screening or initial contact with the study.

2. Women who are $>18$ years of age and are planning pregnancy at the time of screening or initial contact with the study.

3. Women must be residents of the targeted study site at the time of enrollment.

4. Written consent.

Exclusion criteria

1. Women planning pregnancy or at risk of pregnancy who plan to move out of the residents within 1 year of the date of screening.

2. Women planning pregnancy or at risk of pregnancy who are cognitively impaired or mental disease.

\section{Study cohort}

Pregnant women and their partners

Table 2 shows the distribution of maternal and paternal sociodemographic factors as well as the obstetric details of the MOCEH cohort as of February 2009. The 1,229 mothers and fathers included in the study have a mean age of more than 30 years and most of the participants are college graduates. The women were not likely to smoke cigarettes before becoming pregnant, but they were likely to have consumed alcohol. 
Children at birth and overall response

The proportions of girls $(n=438,49.1 \%)$ and boys ( $n=454,50.9 \%)$ were similar. The means of birth weight and gestational age were $3,250 \mathrm{~g}$ and 39 weeks, respectively. The incidence of preterm birth was $3.6 \%$, and $2 \%$ of the newborns had a low birth weight (Table 2).

Approximately $38 \%(n=180)$ of the infants were exclusively breastfed for 6 months. Combined feeding ( $n=273,57.5 \%$ ) was more frequent than bottle feeding $(n=22,4.6 \%)$ (Table 2).

\section{Data collection}

A list of protocols used to assess children up to 5 years of age is shown in Table 3. More detailed information on the MOCEH protocols is available upon request. Information is collected from various sources. Data collections covered under this category are obtained from telephone interviews, self-administered questionnaires, diaries, biological samples, and environmental samples. During routine face-to-face contacts, staff from MOCEH will distribute and provide appropriate instruction and training
Table 2 General characteristics of participants (by the time of February 2009)

\begin{tabular}{|c|c|c|}
\hline Pregnant women and their husbands & Mother & Father \\
\hline Age (year), $N$ (mean $\pm \mathrm{SD})$ & $1209(30.1 \pm 3.8)$ & $1169(31.6 \pm 4.1)$ \\
\hline Maternal height $(\mathrm{cm}), N($ mean $\pm \mathrm{SD})$ & $1045(161.2 \pm 4.7)$ & $1015(173.7 \pm 5.3)$ \\
\hline Maternal weight $(\mathrm{kg}), N($ mean $\pm \mathrm{SD})$ & $1046(59.6 \pm 9.2)$ & $1045(73.6 \pm 10.5)$ \\
\hline \multicolumn{3}{|l|}{ Occupation, $N(\%)$} \\
\hline Yes & $391(37.5)$ & $46(4.6)$ \\
\hline No & $653(62.6)$ & $955(95.4)$ \\
\hline \multicolumn{3}{|l|}{ Maternal educational level (year), $N(\%)$} \\
\hline$<12$ & $218(18.5)$ & $467(38)$ \\
\hline $12-16$ & $756(64.1)$ & $663(54)$ \\
\hline $16+$ & $206(17.5)$ & $99(8.1)$ \\
\hline \multicolumn{3}{|l|}{ Family monthly income (\$US), $N(\%)$} \\
\hline$<200$ & $426(35.1)$ & $260(21.5)$ \\
\hline $200-400$ & $714(59.3)$ & $738(61)$ \\
\hline$>400$ & $68(5.6)$ & $212(17.5)$ \\
\hline \multicolumn{3}{|l|}{ Smoking history, $N(\%)$} \\
\hline Non-smoker & 972 (88.6) & $265(25)$ \\
\hline Smoker & $122(11.2)$ & $796(75)$ \\
\hline \multicolumn{3}{|l|}{ Drinking history, $N(\%)$} \\
\hline Non-drinking & $326(31.3)$ & $135(13)$ \\
\hline Drinker & $716(68.7)$ & $902(87)$ \\
\hline Children & Neonate & 6 month in children \\
\hline \multicolumn{3}{|l|}{ Gender, $N(\%)$} \\
\hline Male & $454(50.9)$ & $191(51.9)$ \\
\hline Female & $438(49.1)$ & $177(48.1)$ \\
\hline Gestational age (mean \pm SD) & $912(39 \pm 1.7)$ & - \\
\hline Weight $(\mathrm{g})$ (mean $\pm \mathrm{SD})$ & $892(3250.9 \pm 435.5)$ & $8.41 \pm 1.2$ \\
\hline Height $(\mathrm{cm})($ mean \pm SD) & $518(50.6 \pm 2.7)$ & $69.48 \pm 3.3$ \\
\hline Preterm, $N(\%)$ & $32(3.6)$ & - \\
\hline Low birth weight, $N(\%)$ & $15(2.0)$ & - \\
\hline \multicolumn{3}{|l|}{ Colostrum feeding, $N(\%)$} \\
\hline Yes & - & $436(91.8)$ \\
\hline No & - & $39(8.2)$ \\
\hline \multicolumn{3}{|l|}{ Feeding method, $N(\%)$} \\
\hline Breast milk & - & $180(37.9)$ \\
\hline Combined feeding & - & $273(57.5)$ \\
\hline Desiccated milk & - & $22(4.6)$ \\
\hline
\end{tabular}


Table 3 Main exposures and outcomes assessed in the MOCEH protocol by period

\begin{tabular}{|c|c|c|c|c|c|c|}
\hline \multirow[t]{2}{*}{ Measurement } & \multirow[t]{2}{*}{ Description } & \multicolumn{2}{|c|}{ Prenatal period (trimester) } & \multicolumn{3}{|c|}{ Postnatal period } \\
\hline & & First & Third & Birth & 6-24 month & $3-5$ year \\
\hline \multicolumn{7}{|l|}{ Exposures } \\
\hline \multirow[t]{2}{*}{ Questionnaire } & $\begin{array}{l}\text { Socio-demographic, medical history, } \\
\text { psychosocial condition, health behavior, } \\
\text { lifestyle and electromagnetic radiation }\end{array}$ & $\vee$ & $\vee$ & & & $\vee$ \\
\hline & Diet $(24 \mathrm{~h}$ or $48 \mathrm{~h}$ recall/FFQ) & $\vee$ & & & $\vee$ & $\vee$ \\
\hline \multicolumn{7}{|c|}{ Environment measurement } \\
\hline & $\begin{array}{l}\mathrm{PM}_{2.5}, \mathrm{PM}_{10} \text { (Indoor, outdoor), } \mathrm{NO}_{2}, \mathrm{HCHO}, \mathrm{VOCs} \\
\text { (Indoor, outdoor and personal), GIS, } \\
\text { questionnaire and daily activity diary }\end{array}$ & $\vee$ & $\vee$ & & $\vee$ & \\
\hline \multicolumn{7}{|l|}{ Biomarkers } \\
\hline \multirow[t]{4}{*}{ Urine } & $\begin{array}{l}\text { 1-hydroxypyrene, 2-naphthol, hippuric acid and } \\
\text { cotinine }\end{array}$ & $\vee$ & $\vee$ & $\vee$ & $\vee$ & $\vee$ \\
\hline & Endocrine disruptor (Bisphenol A and phthalate) & $\vee$ & $\vee$ & $\vee$ & $\vee$ & $\vee$ \\
\hline & Malondialdehyde & $\vee$ & $\vee$ & $\vee$ & $\vee$ & $\vee$ \\
\hline & Genetic (GSTM1/T1) & $\vee$ & & $\vee(C)^{\mathrm{a}}$ & & \\
\hline \multirow[t]{2}{*}{ Blood } & Heavy metals $(\mathrm{Pb}, \mathrm{Hg}, \mathrm{Cd})$ & $\vee(\mathrm{M}, \mathrm{F})^{\mathrm{a}}$ & $\vee(\mathrm{M}, \mathrm{F})^{\mathrm{a}}$ & $\vee(\mathrm{M}, \mathrm{F})^{\mathrm{a}}$ & & $\vee$ \\
\hline & TG, HDL-Cholesterol, Folate & V & $\vee$ & & & \\
\hline \multicolumn{7}{|l|}{ Outcomes } \\
\hline Intrauterine growth & $\begin{array}{l}\text { Biparietal diameter, abdominal circumference, } \\
\text { femur length }\end{array}$ & $\vee$ & $\vee$ & & & \\
\hline Pregnancy outcome & $\begin{array}{l}\text { Preterm, low birth weight, intrauterine growth } \\
\text { retardation and congenital malformation }\end{array}$ & & & $\vee$ & & \\
\hline Postnatal growth & Physical examination (Height, Weight etc.) & & & & & \\
\hline \multirow[t]{4}{*}{ Neurodevelopment } & Maternal IQ test & $\vee$ & $\vee$ & $\vee$ & & \\
\hline & Maternal KASQ & & & & $\vee$ & $\vee$ \\
\hline & Bayley test & & & & $\vee$ & \\
\hline & Leiter International Performance Scale & & & & & $\vee$ \\
\hline \multirow[t]{2}{*}{ Asthma/allergy/atopy } & Questionnaire & & & & $\vee$ & $\vee$ \\
\hline & Child blood (IL-10, Total IgE and Eosinophil) & & & & & $\vee$ \\
\hline
\end{tabular}

${ }^{a} M$ maternal blood, $P$ paternal blood, $C$ cord blood

in the use of materials needed for self-administered data collection.

\section{Assessment of determinants}

\section{Questionnaires}

A questionnaire is administered to collect socio-demographic information, relevant data about the subject's biological, medical and obstetric history, familial history of allergies, whether they were using drugs and vaccinations during pregnancy, and complications related to the current pregnancy. Questions about environmental exposure are asked at 20 or fewer weeks of gestation, 2, 6, 12, 24, and 36 months and then again at 5 years. In addition, the male spouse is asked to complete a questionnaire in order to obtain information on general characteristics, socioeconomic status and environmental factors. Information on breastfeeding, medical history (family, past), nutrition, socioeconomic status, and medical utilization in neonates and infants is obtained from the mother. Table 4 lists the questionnaire items. We developed a web-based system for entering, storing and performing integrative restorations on the data.

\section{Measurements of environmental pollutants}

The quality of air in each participant's home is assessed by measuring the levels of $\mathrm{PM}_{10}, \mathrm{PM}_{2.5}$, volatile organic compounds (VOCs), $\mathrm{HCHO}, \mathrm{NO}_{2}$, bacteria, fungi, endotoxins, noise, humidity, and house dust mites. Each participant's level of exposure to VOCs, $\mathrm{HCHO}$, and $\mathrm{NO}_{2}$ is also measured. The outdoor air quality is estimated using geographic information systems (GIS) mapping.

\section{Biological samples}

Maternal venous blood $(10 \mathrm{ml})$ is collected at 20 weeks of gestation or less. At birth, cord blood and a piece of 
tissue from the umbilical cord are obtained, and the whole placenta is fixed in formalin. Blood samples are not taken from the children until they are 3 years of age. A $100 \mathrm{ml}$ urine sample is collected from the mother at less than 20 weeks of gestation and from the child at $6,12,24$, 36 months and 5 years of age. A $20 \mathrm{ml}$ sample of breast milk is taken at the end of the first feeding on the third day after delivery. No biological samples are assayed without the signed permission of the mother. DNA has been extracted with ethylenediamine tetraacetic acid (EDTA) from blood samples obtained from both mothers and children. Total blood, plasma and serum samples are divided in small aliquots and stored at $-70^{\circ} \mathrm{C}$. Samples of urine, placenta $\left(-20^{\circ} \mathrm{C}\right)$, and breast milk $\left(-70^{\circ} \mathrm{C}\right)$ are stored in freezers until they are delivered to specialized laboratories.

We analyzed creatinine, hs-c-reactive protein, folic acid, high-density lipoprotein cholesterol, triglycerides in blood samples and 1-hydroxypyrene, 2-naphtol, cotinine, hippuric acid, phthalate, bisphenol $\mathrm{A}$, malondialdehyde, and GSTM1/T1 in urine samples obtained from pregnant women during the first and third trimesters. The concentrations of interleukin-10, total IgE and eosinophils in blood samples obtained from children will be assessed, along with the urinary concentrations of phthalate and bisphenol A. We also analyzed the levels of lead, mercury, and cadmium in blood samples obtained from the mothers, fathers and children.

\section{Dietary information}

We collect dietary information by interviewing the mother. Dietary intake during pregnancy is evaluated based on the following two assessments: (i) 24-h recall of dietary intake on the day before a blood test administered within 20 weeks of gestational age and (ii) a semi-quantified food frequency questionnaire (FFQ) on food intake during the year prior to the pregnancy. Every 6 months after birth, mothers are asked about their child's diet during 48-h recall interviews. The FFQ will also be administered when the children are 3 and 5 years of age in order to obtain comprehensive information on their diet. The nutritional and food intakes are quantified using a computer aided nutritional analysis program (CANpro 3.0, Korean Nutrition Society, Seoul, Korea).

Assessment of outcomes

\section{Intrauterine growth}

Fetal biometry (e.g., femur length, head circumference, biparietal diameter and abdominal circumference) was assessed by ultrasonography at 20 or fewer and $30-40$ weeks of gestation in all women.

\section{Birth outcomes}

Medical information, including delivery date, gestational age, delivery mode, cervical length, placenta weight, blood pressure, and complications including premature rupture of membranes, dystocia, cephalopelvic disproportion, breech presentation or other abnormal position, placenta previa, placenta abruption, meconium aspiration syndrome, obstetrical hemorrhage, fetal asphyxia, precipitating labor, preterm birth, cord prolapse or eclampsia during labor, fever, and anesthetic use, was collected from each mother's medical records before and during delivery.

Information on neonatal characteristics at delivery, such as gender, height, weight, and Apgar score at 1 and $5 \mathrm{~min}$, are obtained by clinical examination.

\section{Growth and development}

To monitor and assess growth, we measure each child's height, weight, and head circumference and examine his or her blood pressure every 6 months.

\section{Neurocognitive development}

Neurocognitive development (mental, emotional, and language) is assessed using the Bayley Scales of Infant Development for infants and toddlers, as well as the Age and Stage Questionnaire for infants. After 3 years old, formal intelligence test including Leiter IQ test will be performed. Weschler Intelligence Test for Children(WISC)-Korean version will be tested for 5-year old children.

Atopy, allergy, and asthma in children

The mothers are asked for information on hospital visits due to symptoms of atopy, allergy and asthma using the questionnaire. We also examine each child's dermal condition once every 6 months for the diagnosis of atopic dermatitis. Total IgE in child serum at the age of 3 are measured.

\section{Data quality, control and management}

We established a database of longitudinal measures and a repository of both environmental and biological specimens that will allow future assessments to address important issues concerning clinical and public health outcomes. We monitor the quality of the data periodically and conduct 
Table 4 The variables of questionnaire

\begin{tabular}{|c|c|c|}
\hline Variable & Subject $^{\mathrm{a}}$ & Contents \\
\hline \multicolumn{3}{|l|}{ Basic information } \\
\hline General characteristics & $\mathrm{M}, \mathrm{F}$ & Address, age, height, weight, marital status, number of children and nutritional supplements \\
\hline Health behavior & $\mathrm{M}, \mathrm{F}$ & $\begin{array}{l}\text { Smoking, alcohol consumption, exercise, sleep pattern, stress, and coffee consumption and } \\
\text { dietary habits }\end{array}$ \\
\hline Socioeconomic status & $\mathrm{M}, \mathrm{F}$ & Family income and educational level \\
\hline Medical history & $\mathrm{M}, \mathrm{F}$ & Past medical history, family medical history and drug history \\
\hline Delivery history & M & $\begin{array}{l}\text { Past pregnancy outcome (preterm, low birth weight, spontaneous abortion, induced } \\
\text { abortion and congenital malformation) }\end{array}$ \\
\hline \multicolumn{3}{|l|}{ Environmental information } \\
\hline Environmental factors & $\mathrm{M}, \mathrm{F}$ & Physical agents (EMF, cell phone) and amalgam \\
\hline Outdoor & $\mathrm{M}, \mathrm{F}, \mathrm{N}$ & $\begin{array}{l}\text { Incinerating facility, landfill, sewerage, factory, industries (including the chemical } \\
\text { industry), recognition of air pollution and noise, distance between the participant's house } \\
\text { and the industrial complex and distance from the participant's house to roadways }\end{array}$ \\
\hline Indoor & $\mathrm{M}, \mathrm{F}, \mathrm{N}$ & $\begin{array}{l}\text { Duration of residence, age of building, presence of a humidifier, air conditioner, } \\
\text { ventilation, pet, furniture, carpet, aromatic, and insecticides }\end{array}$ \\
\hline \multicolumn{3}{|l|}{ Delivery information } \\
\hline Medical record & M & $\begin{array}{l}\text { Maternal height and weight (pre pregnancy and at delivery), blood pressure and pregnancy- } \\
\text { related disease }\end{array}$ \\
\hline Information during delivery & M & $\begin{array}{l}\text { Delivery date, body weight just before delivery, gestational age, delivery mode, cervical } \\
\text { length, placenta weight at delivery and blood pressure }\end{array}$ \\
\hline Complications & M & $\begin{array}{l}\text { Premature rupture of membranes, dystocia, cephalo-pelvic disproportion, breech } \\
\text { presentation or other abnormal position, placenta previa, placenta abruption, meconium } \\
\text { aspiration syndrome, obstetrical hemorrhage, fetal asphyxia, precipitating labor, preterm } \\
\text { birth, cord prolapse or eclampsia during labor, fever and anesthetic complications }\end{array}$ \\
\hline Neonates & $\mathrm{N}$ & Gender, length/height, weight, and Apgar score at 1 and 5 min \\
\hline \multicolumn{3}{|c|}{ Neonates and children information } \\
\hline Exposures & $\mathrm{N}, \mathrm{C}$ & $\begin{array}{l}\text { Breastfeeding, health status, medical history (family, past), nutrition, SES and utilization of } \\
\text { hospital }\end{array}$ \\
\hline Outcomes & $\mathrm{N}, \mathrm{C}$ & Height and weight, head circumference, blood pressure, Bayley, IgE and eosinophil count \\
\hline
\end{tabular}

${ }^{\text {a }} M$ mother, $F$ father, $N$ neonates, $C$ children

additional surveys to obtain information regarding questionnaire items that were left blank or insufficiently answered (Table 3).

The MOCEH Database Management System was designed and implemented to handle the special needs of the MOCEH project. We validate each answer or numerical data entry using an automatic screening system in a webbased database program. The training program was given to all field staff members including the interviewers, laboratory technicians and clinicians.

For epidemiological research, accuracy and reliability of the measurements used are extremely important considerations. To insure accurate analysis of the biological samples, internal and external quality controls were used. The internal quality controls included diverse equipment management in the laboratory, temperature monitoring, control, calibration, electricity, and waste treatment. External quality controls included evaluation of laboratory and clinical testing by participating in CAP (College of
American Pathologist) [49], and KSLM (The Korean Society for Laboratory Medicine) [50]. In addition, the samples collected for long term storage have been systematically managed with the BSRS (Biospecimen Storage and Requisition System).

\section{Strengths and limitations}

The standardization of the protocol used in this cohort study will play an important role in the standardization of the study and its future application. Based on the comprehensive information and biological samples collected from cohort subjects, individual studies aiming to elucidate a relevant biological mechanism could be implemented and extended. Repeated measurement of growth, physical and cognitive function, as well as environmental exposures in the early stages of life and childhood will provide a unique and powerful opportunity for etiologic investigation of 
various environmental exposures at various time points as well as their effects on child health.

The ability to assess the influence of multiple environmental exposures on one or more health outcomes is an important characteristic of the MOCEH study. The threshold of toxicity is usually determined based on tests of dose-response relationships related to a single chemical. However, little is known about the synergistic effects of simultaneous exposure to multiple chemicals. Similarly, the investigation of potential interactions between physical, chemical, and psychosocial risk factors is an important focus of the MOCEH study, and one that will require the use of sophisticated analytic approaches. On the other hand, data linkage with an external database that includes administrative data will enhance the availability of information at the community level. However, integrating these databases with the study data may present methodological challenges. In addition, concerns about confidentiality may limit the reporting of specific locations, making linkage to external data more difficult.

\section{Future perspectives}

We cannot over-emphasize that the environment and health of children in Korea need a continuous care in order to establish a sustainable society. Therefore, we have established a prospective cohort study of pregnant women and their children. We expect that this study will provide new information obtained through academic research to support the hypothesis that the gestational environment affects the development of diseases during adulthood. We also expect that the results of this study will enable evaluation of latency and age-specific susceptibility to exposure to hazardous environmental pollutants, evaluation of growth retardation focused on environmental and genetic risk factors, selection of target environmental diseases in children, development of an environmental health index, and establishment of a national policy for improving the health of pregnant women and their children.

The MOCEH study team engages in collaborative research and welcomes future collaborative opportunities. Access to the data is subject to restrictions outlined in the study protocols, and inquiries can be made to the study director or lead researchers with contact details listed on the study website (http://www.moceh.co.kr).

Acknowledgement This study was supported by the Ministry of Environment, Republic of Korea.

Open Access This article is distributed under the terms of the Creative Commons Attribution Noncommercial License which permits any noncommercial use, distribution, and reproduction in any medium, provided the original author(s) and source are credited.

\section{Appendix}

The MOCEH study group includes current members, Ju-Hee Seo, Moon-Hee Chang, Eun Ae Park, Eui Jung Kim, Jae Seon Ryu, kyoung Ae Kong, Ji-Hyun Kim, Bon Sang Koo, Ja Hyeong Kim, Soo Young Bang, Young Joo Lee, Hyun Sook Kwon, Eun Ae Burm, Eun-Jung Kim, Eun-Young Park, Yeni Kim, Hyesook Kim, Ah Young Lee, Hyung In Choi, Heejung Lee, Yo A Lee, Sung Ok Kwon, Yun Kyung Lee.

\section{References}

1. Olsen J, Melbye M, Olsen SF, et al. The Danish National Birth Cohort: its background, structure and aim. Scand J Public Health. 2001;29:300-7.

2. Taylor WR, Newacheck PW. Impact of childhood asthma on health. Pediatrics. 1992;90:657-62.

3. Wadonda-Kabondo N, Sterne JA, Golding J, Kennedy CT, Archer $\mathrm{CB}$, Dunnill MG, et al. A prospective study of the prevalence and incidence of atopic dermatitis in children aged 0-42 months. Br J Dermatol. 2003;149:1023-8.

4. Buxbaum L, Boyle C, Yeargin-Allsopp M, Murphy CC, Roberts HE. Etiology of mental retardation among children ages 3-10: the Metropolitan Atlanta developmental disabilities surveillance program. Atlanta, GA: Centers for Disease Control and Prevention; 2000.

5. Kiely M. The prevalence of mental retardation. Epidemiol Rev. 1987;9:194-218.

6. The Ministry of Environment, Republic of Korea. The Child Health Environmental Research Study (CHEER); 2007.

7. Trasande L, Landrigan PJ. The National Children's Study: a critical national investment. Environ Health Perspect. 2004;112: A789-90.

8. Farrow A, Farrow SC, Little R, Golding J. The repeatability of selfreported exposure after miscarriage. ALSPAC Study Team. Avon Longitudinal Study of Pregnancy and Childhood. Int J Epidemiol. 1996;25:797-806.

9. Magnus P, Irgens LM, Haug K, Nystad W, Skjaerven R, Stoltenberg C, et al. Cohort profile: the Norwegian Mother and Child Cohort Study (MoBa). Int J Epidemiol. 2006;35:1146-50.

10. Ribas-Fitó N, Ramón R, Ballester F, et al. Child health and the environment: the INMA Spanish Study. Paediatr Perinat Epidemiol. 2006;20:403-10.

11. Nakai K, Suzuki K, Oka T, et al. The Tohoku Study of Child Development: a cohort study of effects of perinatal exposures to methylmercury and environmentally persistent organic pollutants on neurobehavioral development in Japanese children. Tohoku J Exp Med. 2004;202:227-37.

12. Rriko K. Exposure to endocrine disrupting chemicals and its adverse effects on the next generation: research approaches and future issues-report based on the outcomes of the Hokkaido study of environment and children's health, (malformations, development \& allergy). International symposium on environmental endocrine disruptors. 2006;9:30-1.

13. Jaddoe VW, van Duijn CM, van der Heijden AJ, Mackenbach JP, Moll HA, Steegers EA, et al. The Generation R Study: design and cohort update until the age of 4 years. Eur J Epidemiol. 2008;23: 801-11.

14. Inskip HM, Godfrey KM, Robinson SM, Law CM, Barker DJ, Cooper C, et al. Cohort profile: the Southampton Women's Survey. Int J Epidemiol. 2006;35:42-8. 
15. Power C, Elliott J. Cohort profile: 1958 British birth cohort (National Child Development Study). Int J Epidemiol. 2006;35: 34-41.

16. Paterson J, Percival T, Schluter P, Sundborn G, Abbott M, Carter S, et al. PIF Study Group. Cohort profile: The Pacific Islands Families (PIF) Study. Int J Epidemiol. 2008;37:273-9.

17. Wadsworth M, Kuh D, Richards M, Hardy R. Cohort profile: The 1946 National Birth Cohort (MRC National Survey of Health and Development). Int J Epidemiol. 2006;35:49-54.

18. Epton MJ, Town GI, Ingham T, Wickens K, Fishwick D, Crane J. New Zealand Asthma and Allergy Cohort Study Group (NZA2CS). The New Zealand Asthma and Allergy Cohort Study (NZA2CS): assembly, demographics and investigations. BMC Public Health. 2007;7:26-34.

19. The Ministry of Environment, Republic of Korea. National Environmental Health Action Plan (NEHAP); 2005.

20. Ha EH, Hong YC, Lee BE, Woo BH, Schwartz J, Christiani DC. Is air pollution a risk factor for low birth weight in Seoul? Epidemiology. 2001;12:643-8.

21. Lee BE, Ha EH, Park HS, Kim YJ, Hong YC, Kim H, et al. Exposure to air pollution during different gestational phases contributes to risks of low birth weight. Hum Reprod. 2003;18: 638-43.

22. Lee BE. Air pollution and low birth weight in Seoul. Ph.D. Dissertation. Ewha Womans University; 2002.

23. Lee BE, Park HS, Park EA, Hong YC, Ha EH. Air pollution exposure and health effects in fetus. J Prev Med Public Health. 2004;37:291-9.

24. Kim YJ, Hong YC, Lee KH, Park HJ, Park EA, Moon HS, et al. Oxidative stress in pregnant women and birth weight reduction. Reprod Toxicol. 2005;19:487-92.

25. Kim YJ, Park HS, Park MH, Suh SH, Pang MG. Oxidative stressrelated gene polymorphism and the risk of preeclampsia. Eur $\mathbf{J}$ Obstet Gynecol Reprod Biol. 2005;119:42-6.

26. Kim YJ, Lee BE, Park HS, Kang JG, Kim JO, Ha EH. Risk factors for preterm birth in Korea: a multicenter prospective study. Gynecol Obstet Invest. 2005;60:206-12.

27. Suh YJ, Kim BM, Park BH, Park HS, Kim YJ, Kim H, et al. Cytochrome P450IA1 polymorphisms along with PM(10) exposure contribute to the risk of birth weight reduction. Reprod Toxicol. 2007;24:281-8.

28. Kim OJ, Ha EH, Kim BM, Seo JH, Park HS, Jung WJ, et al. PM10 and pregnancy outcomes: a hospital-based cohort study of pregnant women in Seoul. J Occup Environ Med. 2007;49: 1394-402.

29. Kwon WY. Globalization and the sustainability of cities in the Asia Pacific region: the case of Seoul. Tokyo: UN University Press; 2001.

30. Jangwon JIN, Gumdan-Ri IM, Chungju CB. An empirical study on survey and impact analysis of local development by car free streets in Korea. J East Asia Soc Transp. 2003;5:66-78.

31. Hong SY. Assessment of coastal zone issues in the Republic of Korea. Coast Manag. 1991;19:391-415.

32. Lee JT, Shin D, Chung Y. Air pollution and daily mortality in Seoul and Ulsan, in Korea. Environ Health Perspect. 1999;107: 149-54.

33. Son JY, Cho YS, Lee JT. Effects of air pollution on postneonatal infant mortality among firstborn infants in Seoul, Korea: casecrossover and time-series analyses. Arch Environ Occup Health. 2008;63:108-13.
34. Woodruff TJ, Darrow LA, Parker JD. Air pollution and postneonatal infant mortality in the United States, 1999-2002. Environ Health Perspect. 2008;116:110-5.

35. Dales RE, Cakmak S, Doiron MS. Gaseous air pollutants and hospitalization for respiratory disease in the neonatal period. Environ Health Perspect. 2006;114:1751-4.

36. Rodriguez C, Tonkin R, Heyworth J, Kusel M, De Klerk N, Sly PD, et al. The relationship between outdoor air quality and respiratory symptoms in young children. Int J Environ Health Res. 2007; 17 : 351-60.

37. Sikorski R, Paszkowski T, Szprengier-Juszkiewicz T. Mercury in neonatal scalp hair. Sci Total Environ. 1986;57:105-10.

38. Hernandez-Avila M, Peterson KE, Gonzalez-Cossio T, Sanin LH, Aro A, Schnaas L, et al. Effect of maternal bone lead on length and head circumference of newborns and 1-month-old infants. Arch Environ Health. 2002;57:482-8.

39. Needham LL, Barr DB, Caudill SP, Pirkle JL, Turner WE, Osterloh $\mathrm{J}$, et al. Concentrations of environmental chemicals associated with neurodevelopmental effects in U.S. population. Neurotoxicology. 2005;26:531-45.

40. Seidler A, Raum E, Arabin B, Hellenbrand W, Walter U, Schwartz FW. Maternal occupational exposure to chemical substances and the risk of infants small-for-gestational-age. Am J Ind Med. 1999;36:213-22.

41. Sikorski R, Juszkiewicz T, Paszkowski T, Szprengier-Juszkiewicz T. Women in dental surgeries: reproductive hazards in occupational exposure to metallic mercury. Int Arch Occup Environ Health. 1987;59:551-7.

42. Ashby J, Tinwell H. Uterotrophic activity of bisphenol A in the immature rat. Environ Health Perspect. 1998;106:719-20.

43. Calafat AM, Kuklenyik Z, Reidy JA, Caudill SP, Ekong J, Needham LL. Urinary concentrations of bisphenol A and 4-nonylphenol in a human reference population. Environ Health Perspect. 2005;113:391-5.

44. Howdeshell KL, Hotchkiss AK, Thayer KA, Vandenbergh JG, vom Saal FS. Exposure to bisphenol A advances puberty. Nature. 1999;401:763-4.

45. Lee YJ, Ryu HY, Kim HK, Min CS, Lee JH, Kim E, et al. Maternal and fetal exposure to bisphenol A in Korea. Reprod Toxicol. 2008;25:413-9.

46. Nagel SC, vom Saal FS, Thayer KA, Dhar MG, Boechler M, Welshons WV. Relative binding affinity-serum modified access (RBA-SMA) assay predicts the relative in vivo bioactivity of the xenoestrogens bisphenol A and octylphenol. Environ Health Perspect. 1997;105:70-6.

47. Engel SM, Zhu C, Berkowitz GS, Silva MJ, Miodovnik A, et al. Prenatal phthalate exposure and performance on the Neonatal Behavioral Assessment Scale in a multiethnic birth cohort. Neurotoxicology. 2009;4:16.

48. Suh YJ, Kim BM, Park BH, Park H, Kim YJ, Kim H, et al. Cytochrome P450IA1 polymorphisms along with PM(10) exposure contribute to the risk of birth weight reduction. Reprod Toxicol. 2007;24:281-8.

49. American Medical Association and College of American Pathologists. College of American Pathologists (CAP)/Physician Consortium for Performance Improvement. Pathology, Physician Performance Measurement Set.; 2007.

50. Lee WG, Kwak YS, Lee DH, Hwang YS, Lee KN. Laboratory inspection and accreditation in Korea II. Korean J Lab Med. 2003;23:363-9. 